\title{
1 Characterization of the Rate of Change of Rheological Properties of Nano-Modified
}

\section{Asphalt}

3

4 Ali Jamshidi ${ }^{1}$, Mohd Rosli Mohd Hasan ${ }^{2},{ }^{3}$, Hui Yao ${ }^{2}$, Zhanping You ${ }^{2, *}$ and Meor Othman

5 Hamzah $^{3}$

6

$7{ }^{1}$ Post-Doctoral International Research Fellow of the Japan Society for the Promotion of the

8 Science (JSPS), Faculty of Engineering Hokkaido University, Kita 13, Nishi 8, Kita-ku, Sapporo,

9 Hokkaido, 060-8628, Japan

10

$11{ }^{2}$ Department of Civil and Environmental Engineering, Michigan Technological University, 1400

12 Townsend Drive, Houghton, Michigan 49931, USA

13

$14{ }^{3}$ School of Civil Engineering, Universiti Sains Malaysia, Engineering Campus, 14300 Nibong

15 Tebal, Seberang Perai Selatan, P. Pinang, Malaysia

16

17 *Corresponding Author: Email: zyou@mtu.edu; Phone: 906-487-1059

18 Abstract: This study aims to characterize the rate of change that takes place in the rheological 19 properties of asphalt binders modified with numerous types and contents of nano-materials. The 20 effects of nano-materials on the activation energy of modified asphalt binders under the viscous

21 and visco-elastic behavior were also investigated. Through the research findings, the application

22 of non-dimensional analyses using relative viscosity and relative $\mathrm{G}^{*} / \sin \delta$ (NSRP) are very 23 meaningful to evaluate the rate of change in the rheological properties of asphalt binder per one 
1 unit percent of nano-material. It is also found that the non-dimensional viscosity index $(\nabla \eta)$ and

2 non-dimensional Superpave ${ }^{\mathrm{TM}}$ rutting factor gradient ( $\mathrm{NNSRP}$ ) are influenced by the type and

3 content of nano-material, and test temperature. The activation energy analysis has confirmed that

4 the changes in amount of energy consumed are not only influenced by the type and content of

5 nano-material, but also the physical phase of the modified asphalt binders.

6

7 Key words: Nano-modifiers, viscous, visco-elastic, non-dimensional analyses, activation energy

8

9

10 


\section{Introduction}

Nanotechnology encompasses techniques, devices and systems that are associated with

3 the nanometer scale. Nanotechnology is widely used to develop a new generation of materials

4 with superior performance to enhance the macroscopic properties of materials [1-4]. Mulenga

5 and Robery [5] stated this technology provides access to the world of the tiniest particle in civil

6 engineering, where the dimension of the materials fall under the range of 1-100nm for at least

7 one side of the particle dimension. Due to its miniature size and high surface area, the reactivity

8 of Nano-material is typically higher compared to normal size materials, which is beneficial to

9 improve the rheological properties of asphalt binders and engineering properties of asphalt 10 mixtures.

According to You et al. [6], although engineers and road builders are more interested in

12 material behavior at meso and micro scales, the micro and Nano scales provide fundamental

13 insight for the enhancement of science and technology. In the asphalt pavement industry, various

14 types of Nano-materials have been developed and used, including Nano-silica powder [7],

15 carbon Nano-fibers [8, 9], carbon Nano-tubes [10-13], non-modified and polymer modified

16 Nano-clay [6, 14-16], as well as polysiloxane-modified montmorillonite [16, 17]. The

17 application of Nano-materials as asphalt modifier is growing rapidly due to its unique

18 characteristics that significantly improve the performance of asphalt binder. Based on a study by

19 Cheng et al. [18] on the effects of micro and Nano-size hydrated lime on warm mixture asphalt

20 (WMA) performance, it was found that the Sasobit ${ }^{\circledR}$ WMA mixtures that incorporated Nano-size

21 hydrated lime had a significant increase in indirect tensile strength (ITS), toughness and flow

22 number in both, dry and wet conditions compared to specimen containing micro-size hydrated 23 lime. 

polymer modified Nano-clay have higher stiffness and lower deflection than the specimen

3 prepared using base asphalt binder, which indicated a better resistance to rutting. Nazzal et al.

4 [19] also revealed that Nano-clay material increases the adhesive forces of the asphalt binder,

5 however slightly decreases the cohesive force. Goh et al. [20] studied the synergistic effects of

6 Nano-clay and micro-carbon fiber on the moisture sensitivity of asphalt mixture in terms of 7 tensile strength ratio (TSR). The results indicated that the TSR values of all mixtures containing

8 Nano-clay as well as micro-carbon fiber are greater than the recommended TSR value, with the 9 minimum value of 0.9. Goh et al. [20] also investigated the effects of $\mathrm{NaCl}, \mathrm{MgCl}_{2}$ and $\mathrm{CaCl}_{2}$, 10 as deicers, on the tensile strength of Nano-clay and micro-carbon fiber modified mixtures. The 11 results showed that the incorporation of $1.5 \%$ Nano-clay material in the mixtures have increased 12 the tensile strength of the tested specimens, hence the mixtures are able to endure the effects of 13 deicer materials on asphalt pavement. Yao et al. [16] studied the effects of short-term aging on asphalt binders incorporating nanomer I.44P, micro-carbon fiber, non-modified Nano-clay and polymer-modified Nano-clay in 16 terms of aging index. The results indicated that addition of Nano-clay powder reduced the aging 17 impact on asphalt binder. This result is consistent with the Fourier Transform Infra-red 18 Spectroscopy (FTIR) outputs indicating lower carbonyl index in the modified asphalt binder. 19 Khattak et al. $[9,21]$ studied the effects of carbon Nano-fiber (CNF) on rheological properties of 20 asphalt binders and performance of asphalt mixtures. The results indicated that presence of CNF 21 in asphalt binder will significantly enhance the rheological properties of asphalt binders in terms 22 of viscosity, $\mathrm{G} * / \sin \delta$ and fatigue life. The results also showed that CNF modified mixtures have 23 higher dynamic modulus, ITS, stiffness and fatigue life as compared to control samples. 
Based on previous studies, there are several impacts on rheological properties and performance of Nano-material modified asphalt binders and mixtures that can be observed through various mechanisms. Such materials may have identical effects on a given rheological properties; however lack of suitable parameter(s) to present the data and enable precise assessment on the rate of change of the rheological characteristics of the Nano-modified binders should be taken into consideration. This paper attempts to fill this gap via proposal of new parameters based on the rheological properties of asphalt binders that enable researchers to characterize sensitivity of the Nano-modified binders based on the independent variables such as Nano-material type, content, test temperature and binder type.

\section{New Parameters and Aspects}

As previously mentioned, appropriate parameters are required to assess the rate of change of modified asphalt binders' rheological properties, which can be used as indicator(s) that govern the change of asphalt binders' behavior in details. However, proposal of such parameters is not an easy task to realize since different asphalt binder types and sources may result in different rheological properties, especially after the modification with Nano-materials. Consequently, the changes in the performance of the Nano-modified asphalt binders might differ depending on the properties of the base or control binders. So, the rheological properties of a given control or unmodified binder (assumed as initial or boundary condition) could differ from binder to binder or from one source to the other, as schematically illustrated in Fig. 1. Under this circumstance, it is essential to standardize a boundary condition via omitting the effect of rheological properties of control asphalt binders through a method called non-dimensional analysis. This method also creates easier comparison between asphalt binder samples incorporating various types of Nano- 
1 materials in terms of the amount of changes in the desired rheological properties. A same idea

2 also can be applied while evaluating a similar type Nano-modified asphalt binder that is prepared 3 at different percentages.

4

Fig. 1.

Table 1 presents another example to provide a better understanding. From Table 1, it can

8 be seen that asphalt $\mathrm{A}$ has higher viscosity compared to asphalt B. After going through a 9 modification, the viscosity of both binders has proportionally decreased, which indicates an 10 identical effect on both binders. However, it is unfeasible to compare the performance of 11 modified binder in terms of reduction in viscosity due to the initial conditions of the binders 12 (initial viscosity of unmodified binders). So, it is essential to provide a standardized initial 13 condition for both binders using a non-dimensional analysis.

14 From the result presented in Table 1, the incorporation of a modifier has decreased the 15 viscosity of asphalt $\mathrm{A}$ by $10.20 \%$ at $120^{\circ} \mathrm{C}$ as compared to its initial condition, while the 16 corresponding value is $11.81 \%$ for the modified asphalt B in comparison with its initial state.

17 Additionally, the changes observed from the relative viscosity over a temperature range also can 18 be used to compare the rheological behavior of different Nano-material modified asphalt binders. 19 For example, Table 1 shows that although the performance of asphalt A in terms of viscosity 20 reduction is identical at $140^{\circ} \mathrm{C}$ and $150^{\circ} \mathrm{C}$ (as in column 7), it is significantly different for asphalt 21 B at the same temperatures. Even though, decreasing trend can be observed in the viscosity of 22 both binders, the rates of reduction are different. 


\section{Table 1.}

This study attempts to propose simple parameters that allow researchers to characterize

4 and compare the rate of change in asphalt binders modified using different types of Nano-

5 materials. As a visco-elastic material, asphalt binders exhibit different behaviors, which are

6 highly influences by temperature and loading time. A rheological property is chosen to represent

7 the viscous behavior based on the results generated from the rotational viscosity test. Another

8 parameter based on the Superpave ${ }^{\mathrm{TM}}$ rutting factor was selected to signify the combination of

9 viscous and elastic (visco-elastic) criteria, named as non-dimensional viscosity index and

10 gradient of non-dimensional Superpave ${ }^{\mathrm{TM}}$ rutting factor, respectively.

11 Furthermore, given that adding Nano-materials changes the rheological properties of 12 asphalt binders, it also might lead to changes in the intermolecular forces within the asphalt 13 binder structures. Since the role of Nano-material type and content on the intermolecular forces 14 of the modified binders have not been investigated in great details, it has created a new intention 15 to evaluate the effects of Nano-material type and content on intermolecular forces in terms of 16 activation energy. Molecular models are known to have excellent agreement with experimental 17 values obtained by Nano indentation techniques [22]. The results of the activation energy 18 analysis are useful in preparing a micro-model of inter-molecular forces of asphalt binders 19 modified using Nano-materials.

20

21 3. Material and Methods

$22 \quad 3.1 \quad$ Specimen Preparation 

asphalt in this study. It is noted, this control asphalt formerly was modified using acrylonitrile

3 butadiene styrene (ABS) prior to meeting the lower temperature requirement, as well as to

4 improve the compatibility between the polymer and asphalt. The Nano-materials as listed in

5 Table 2 were used to modify the control asphalt binder. Fig. 2 shows the physical appearance of

$6 \quad$ Nano-modifiers used in this study.

7 In the sample preparation, the Nano-material modifier was added to the control binder at

8 designated concentrations (Table 2) based on the mass of asphalt binder. The modified asphalt

9 binder was mixed using a high shear mixer (Silverson L4RT-A laboratory mixer) at 4000rpm

10 rotational speed for two hours at $130^{\circ} \mathrm{C}$. Prior to mixing, the asphalt binder was melted in an

11 oven at approximately $135^{\circ} \mathrm{C}$.

\section{Table 2.}

\section{Fig. 2.}

\section{$17 \quad 3.2 \quad$ Asphalt Binder Tests}

A Brookfield rotational viscometer (RV) was used to determine the viscosity of control and Nano-modified asphalt binders at temperatures ranging from $100^{\circ} \mathrm{C}$ to $190^{\circ} \mathrm{C}$. The $\mathrm{RV}$ test is

20 also typically used to determine the mixing and compaction temperatures based on the ideal

21 viscosities for both processes in the construction stage. The basic idea of this issue was clearly

22 discussed by Haider et al.[23], where in the state of below ideal condition, the layers of the fluid 23 molecules slide over each other as the fluid flows, however the existence of intermolecular 
1 forces resist the motion of the fluid-as shown schematically by dash line and letter $\mathrm{f}_{1}$ and $\mathrm{f}_{2}$ in

2 Fig. 3(a). Therefore, in the initial condition for fluid to begin flowing, the minimum required

3 energy defined as activation energy (AE) should be higher than the intermolecular forces, where,

4 higher $\mathrm{AE}$ indicates that more energy is required to initiate the flow, as presented by $\mathrm{F}$ in Fig.

5 3(b). The activation energy was calculated based on the Arrhenius Equation shown in Equation

61.

7

$8 \quad v=A e^{\frac{E_{f}}{R T}}$

9

Where $v$ is the viscosity (Pas), $\mathrm{A}$ is a regression constant, $\mathrm{E}_{\mathrm{f}}$ is the activation energy for

11 flow $(\mathrm{kJ} / \mathrm{mol}), \mathrm{T}$ is temperature $\left({ }^{\circ} \mathrm{K}\right)$ and $\mathrm{R}$ is the universal gas constant $\left(8.34 \mathrm{~J} / \mathrm{mol} /{ }^{\circ} \mathrm{K}\right)$. The

12 rheological properties of asphalt binders at intermediate temperatures have been evaluated in

13 terms of complex modulus $\left(\mathrm{G}^{*}\right)$ and the phase angle $(\delta)$ using the dynamic shear rheometer

14 (DSR). The tests were conducted under two different conditions, named as temperature sweep

15 and frequency sweep. Basically the temperature sweep test was performed under a wide range of

16 temperatures, from $46^{\circ} \mathrm{C}$ to $82^{\circ} \mathrm{C}$ at $6^{\circ} \mathrm{C}$ increments. Meanwhile, the frequency sweep test was

17 conducted at various frequencies ranging from $0.01 \mathrm{~Hz}$ to $100 \mathrm{~Hz}$ at a temperature range from $18 \quad 46^{\circ} \mathrm{C}$ to $70^{\circ} \mathrm{C}$ with increments of $6^{\circ} \mathrm{C}$.

19

Fig. 3.

21

\section{4. Results and Discussions}

$23 \quad 4.1 \quad$ Rotational Viscosity 
Fig. 5 shows the viscosity curves of asphalt binders prepared using different Nano-

2 index has been proposed as expressed by Equations 2 and 3.

22

$23 \quad \eta=\left(\frac{v}{v_{\mathrm{C}}}\right)$

\section{Table 3.}

Even though the application of Nano-materials changed the viscosity of the asphalt binders, the degree of change varied. In order to compare and characterize the rate of change in the rheological properties of modified binders in terms of viscosity, a non-dimensional viscosity 
$2 \quad \nabla \eta=\left[\frac{\delta \eta_{N}}{\delta N}\right]=\left[\frac{\Delta \eta_{N}}{\Delta N}\right]=\left[\frac{\eta_{N}-\eta_{C}}{N}\right]$

3

4

6

Where $\eta$ is the relative viscosity of the Nano-modified asphalt binder; $v$ is the viscosity of the Nano-modified asphalt binder; $v_{\mathrm{C}}$ is the viscosity of the control binder; and $\nabla \eta$ is the nondimensional viscosity index. In addition, the $\nabla \eta$ is used to determine the effect of adding one unit percent Nano-material on the asphalt binder's viscosity at each test temperature.

\section{Fig. 4.}

Fig. 5 illustrates the relationship between $\nabla \eta$ and temperature for each Nano-modified asphalt binder. The $\nabla \eta$ values of asphalt binders incorporating various Nano-materials are different from each other. For instance, at $100^{\circ} \mathrm{C}$, the $\nabla \eta$ values of MCF2, NPMN2 and NI.44P2 binders are approximately $+21.42 \%,+72.29 \%$ and $+20.34 \%$, respectively. These results indicate that incorporating $1 \% \mathrm{MCF}, \mathrm{NPMN}$ and NI.44P increases the asphalt's relative viscosity by $21.42 \%, 72.29 \%$ and $20.34 \%$, respectively. Furthermore, the $\nabla \eta$ results also indicate that adding $1 \% \mathrm{MCF}, \mathrm{NPMN}$ and NI.44P increases the relative viscosity of MCF4, NPMN4 and NI.44P4 modified binders by $6.49 \%, 107.03 \%$ and $53.14 \%$, respectively, at the same test temperature. This means that the change in performance caused by adding one unit percent of Nano-materials in various content $(2 \%$ and $4 \%)$ can vary for the same Nano-material type and test temperature, when measured in terms of $\nabla \eta$.

The performance of asphalt binder incorporating Nano-materials is proportionally changed depending on the test temperatures. For instance, the $\nabla \eta$ of NPMN2 binder decreases 
1 from $51.87 \%$ to $42.08 \%$ when the test temperature increases from $125^{\circ} \mathrm{C}$ to $135^{\circ} \mathrm{C}$. This

2 reduction (approximately 19\%) implies that the temperature has a significant impact on the

3 relative viscosity of the asphalt binder.

$4 \quad$ From Figs. 5(c) and 5(e), the viscosity of NS4, NS6 and PMN4 binders are lower than the 5 control binder; therefore, the $\nabla \eta$ values for such binder samples are negative. For instance, the

$6 \nabla \eta$ of PMN4 and NS4 binders is $-2.94 \%$ and $-9.25 \%$, respectively, at $175^{\circ} \mathrm{C}$. This indicates by

7 adding $1 \%$ polymer modified Nano-clay and Nano-silica it decreases the relative viscosity of

8 PMN4 and NS4 binders by $2.94 \%$ and $9.25 \%$ at $175^{\circ} \mathrm{C}$, which is similar to the effects of Sasobit ${ }^{\circledR}$ 9 in asphalt binder [24].

10

\section{Fig. 5.}

Three different trends can be observed from the relationships between $\nabla \eta$ and temperature. The first trend indicates that $\nabla \eta$ decreases linearly as the temperature increases, as shown by MCF2, NPMN2 and NPMN4, as well as NI.44P4 binders in Figs. 5(a) to 5(c), respectively. Figs. 5(a), 6(c) and 6(d) define the second trend, in which the $\nabla \eta$ values are scattered with the average values, $+5.51 \%,+20 \%$ and $-2.42 \%$, for MCF4, NI.44P2 and PMN4 binders, respectively. In other words, MCF4, NI.44P2 and PMN4 binders are temperature independent in terms of $\nabla \eta$, which means changes in the rate of change of relative viscosity with the addition of one unit percent of Nano-materials is not a function of temperature. The third trend is that $\nabla \eta$ increases linearly when temperature increases for NS6 binder, as shown in Figure 5(d). However, no obvious trends have been presented by PMN2 and NS4 as shown in Figs. 5(d) and 5(e). For example, the $\nabla \eta$ of PMN2 binder is $+2.81 \%$ at $100^{\circ} \mathrm{C}$, while at $125^{\circ} \mathrm{C}$, the value 
1 equals $-4.08 \%$. Evaluating the change of relative viscosity caused by incorporating a $1 \%$ additive

2 in terms of $\nabla \eta$ can be complicated.

3

$4 \quad 4.2 \quad$ Visco-elastic Properties

5

Figs. 6 and 7 show that most of the modified binders have a lower $G^{*}$ and higher $\delta$

6 compared to the control binders at various test temperatures and frequencies. However, Figs. 6

7 and 7 show that the G*of MCF2 is higher than those of the control samples. Fig. 8 presents the

$8 \mathrm{G}^{*} / \sin \delta$ of asphalt binder samples at various test temperatures. Although N144P2 has a higher

$9 \mathrm{G}^{*} / \sin \delta$ at $46^{\circ} \mathrm{C}$, it is lower than the control binder at the other temperatures. Moreover, MCF2

10 has the maximum $\mathrm{G}^{*} / \sin \delta$, therefore, MCF2 is less prone to rutting in terms of $\mathrm{G}^{*} / \mathrm{sin} \delta$

11 compared to the other binder samples.

12 Fig. 8 also shows that the minimum $\mathrm{G}^{*} / \sin \delta$ at $46^{\circ} \mathrm{C}$ is presented by PMN4, meanwhile

13 the NS6 sample has the minimum $\mathrm{G}^{*} / \sin \delta$ at temperature range of $52^{\circ} \mathrm{C}$ to $82^{\circ} \mathrm{C}$. This indicates

14 that the $\mathrm{G}^{*} / \sin \delta$ (a parameter that is typically used to evaluate the rutting performance of asphalt

15 pavements) of the Nano-modified asphalt binders are influenced by the type and amount of 16 Nano-materials, which is consistent with the results reported by Nazzal et al., [19] and You et al. 17 [6].

18

\section{Fig. 6.}

20

21

To characterize the rate of change due to the effects of Nano-materials on $\mathrm{G}^{*} / \mathrm{sin} \delta$, the 22 gradient of the non-dimensional Superpave ${ }^{\mathrm{TM}}$ rutting factor is defined by Equations 4 and 5. 
$1 \quad \mathrm{NSRP}=\left[\mathrm{G}^{*} / \operatorname{Sin}(\delta)\right]_{\mathrm{n}}=\frac{\left[\mathrm{G}^{*} / \sin \delta\right]_{\mathrm{s}}}{\left[\mathrm{G}^{*} / \sin \delta\right]_{\mathrm{C}}}$

$3 \quad \nabla \mathrm{NSRP}=\left[\frac{\partial \mathrm{NSRP}}{\partial \mathrm{S}}\right]=\left[\frac{\Delta \mathrm{NSRP}}{\Delta \mathrm{S}}\right]=\left[\frac{\mathrm{NSRP}_{\mathrm{S}_{\mathrm{i}+1}}-\mathrm{NSRP}_{\mathrm{S}_{\mathrm{i}}}}{\mathrm{S}_{\mathrm{i}+1}-\mathrm{S}_{\mathrm{i}}}\right]$

4

5 Where, the $\left[\mathrm{G}^{*} / \sin (\delta)\right]_{\mathrm{S}}$ and $\left[\mathrm{G}^{*} \sin (\delta)\right]_{\mathrm{C}}$ are $\mathrm{G}^{*} / \sin (\delta)$ of asphalt binders incorporating

6 Nano-material additives and control asphalt binder, respectively. Then, the $\mathrm{NSRP}_{\mathrm{S}_{i+1}}$ and $\mathrm{NSRP}_{\mathrm{S}_{i}}$

7 are the relative Superpave $\mathrm{TM}^{\mathrm{TM}}$ rutting factors of asphalt binders incorporating nano-materials and

8 control asphalt binders, respectively. The denominator of the fraction in Equation 5 shows the

9 differences of Nano-material content. Moreover, theVNSRP presents the gradient of relative

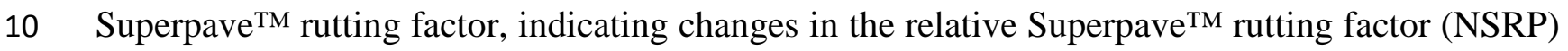

11 per one unit percent Nano-material.

12

13

14

Fig. 7.

\section{Fig. 8.}

asphalt binder samples in terms of the relative Superpave ${ }^{\mathrm{TM}}$ rutting factor at each test temperature when one unit percent (1\%) Nano-material is added. Fig. 9 shows the relationship between $\nabla N S R P$ and test temperatures.

\section{Fig. 9.}


From Fig. 9(a), the DNSRP of MCF2 is positive, indicating that adding $1 \%$ carbon micro-

fiber increases the relative $\mathrm{G}^{*} / \sin \delta$ irrespective of test temperature. For example, $1 \%$ carbon micro-fiber increases the relative $\mathrm{G}^{*} / \sin \delta$ by $9.13 \%$ at $58^{\circ} \mathrm{C}$, while adding $1 \%$ carbon microfiber to the asphalt binder decreases the relative $\mathrm{G}^{*} / \sin \delta$ of MCF4 binder by $7.09 \%$ at $58^{\circ} \mathrm{C}$. Furthermore, the results also show that incorporating $1 \%$ polymer modified Nano-clay, nonmodified polymer Nano-clay, nanomer I.44P and Nano-silica will decrease the relative G*/sin $\delta$ of NPMN2, MCF4, N144P4 and NS4 binders by $12.15 \%, 7.09 \%, 5.4 \%$ and $11.49 \%$ at $58^{\circ} \mathrm{C}$, respectively. This indicates the softening effect of the Nano-materials on asphalt binder by lowering the relative $\mathrm{G}^{*} / \sin \delta$ of the asphalt binders.

Analysis of DNSRP could also be used to show the effects of elevated temperature on the performance of Nano-materials. As an example, the $\nabla N S R P$ of NPMN4 is $-5.90 \%$ at $64^{\circ} \mathrm{C}$ (Fig. 9(b)), while the corresponding value is $-1.53 \%$ at $82^{\circ} \mathrm{C}$; this $4.37 \%$ increase in $\nabla N S R P$ can be attributed to the effects of an $18^{\circ} \mathrm{C}$ increased in test temperature. Fig. 9(c) also shows that the $\nabla N S R P$, rate of change in the relative $\mathrm{G}^{*} / \sin \delta$, of NI.44P2 is negative beyond $58^{\circ} \mathrm{C}$, or high temperature performance grade of the base binder. Therefore, adding $1 \%$ nanomer I.44P increases the relative $\mathrm{G}^{*} / \sin \delta$ of NI.44P2 up to $58^{\circ} \mathrm{C}$, while it reduces the relative $\mathrm{G}^{*} / \sin \delta$ of the binder above $58^{\circ} \mathrm{C}$. Hence, $58^{\circ} \mathrm{C}$ is defined as a critical temperature for NI.44P2. As a result, when a Nano-material is chosen as a modifier of asphalt binder, it may increase the rutting resistance of the asphalt binder at a specific temperature range, while it may have detrimental effects at other temperature ranges. Thus, the Nano-material type should be selected with care, and the preparation temperature of asphalt binders should also be taken into consideration. 


\subsection{Activation Energy}

Tables 4 and 5 show the activation energy of asphalt binders using RV and DSR tests through a wide range of temperatures. The results show that some of the modified asphalt binders have higher activation energy, but some have lower activation energy level compared to the control binder. Furthermore, it is also found that the NPMN4 binder has the maximum activation energy $(72808.19 \mathrm{~kJ} / \mathrm{mol})$ based on the RV test results, meanwhile NI.44P4 has the maximum activation energy $(91404.11 \mathrm{~kJ} / \mathrm{mol})$ using the DSR results. Higher activation energy (based on the RV test results) indicates that higher energy is required to overcome intermolecular forces to ensure the asphalt binder flow. Therefore, the intermolecular forces in MCF2, MCF4, NPMN2, NPMN4, PMN2, NI.44P2, NI.44P4 were higher than the control binder sample, while PMN4, NS4, and NSF6 showed lower forces in activation energy when using the RV results. Table 4 also shows that adding more Nano-material content increase the activation energy, depending on Nano-material type. For example, adding 2\% extra NPMN has increased the activation energy by $9.41 \%$ based on RV test results, however incorporating $2 \%$ extra PMN has reduced the activation energy by $3.51 \%$.

The maximum activation energy based on the outputs of the DSR results can be also conclude more energy is required to overcome intermolecular forces when the binder samples follow visco-elastic behavior. From Table 5, it can be seen that the amount of activation energy computed using the DSR results are higher than those using RV results. This occurred because the binder samples are viscous due to the high temperatures of the RV test and intermolecular forces are weakened due these high temperatures. In contrast, the molecular forces are higher in the visco-elastic phase of binder due to lower temperature at the DSR test. Therefore, to study the effects of the activation energy on asphalt binders, a wide temperature ranges should be 
1 considered. For example, NPMN4 and NS6 showed the highest and the lowest activation

2 energies based on RV results, respectively, but NI.44P4 and NPMN2 had the largest and smallest

3 activation energies using DSR results. As a consequence, this change in performance of Nano-

4 materials in terms of the amount activation energy can be attributed to the Nano-material type

5 and content. It can also be attributed to the interaction of the Nano-material with asphalt

6 molecule, which depends on the type of Nano-material, content and physical phase of binder that

7 is a function of temperature.

8

\section{5. Conclusions}

\section{Table 4.}

\section{Table 5.}

Overall, the intentions of this paper are to characterize the rate of change in rheological properties and evaluate the activation energy of asphalt binders that incorporate Nano-modifiers based on three specific objectives. This includes a proposal of parameters to characterize the rate of change in the rheological properties of asphalt binder incorporating different types of Nanomodifiers at various test temperatures using non-dimensional analysis. It was followed by an evaluation on the effects of intermolecular forces of Nano-modified asphalt binders when asphalt behaves as a viscous and visco-elastic material. Two parameters were used to characterize the changes in the rheological properties of Nano-modified asphalt binders, namely non-dimensional viscosity index $(\nabla \eta)$ and gradient of relative Superpave ${ }^{\mathrm{TM}}$ rutting factor ( $\left.\nabla N S R P\right)$. 

temperature. Furthermore, three trends were observed from $\nabla \eta$ versus temperature curves that 3 depend on Nano-material type and content. Such trends can be used to compare and characterize 4 how one unit percent Nano-materials change the viscosity of the modified asphalt binders. The $5 \nabla \eta$ also indicates that the performance of some Nano-materials at specific temperatures can be 6 comparable with WMA additives that lower the viscosity of asphalt binders. Based on the relative gradient of the Superpave ${ }^{\mathrm{TM}}$ factors, it was found that only the 8 micro-carbon fibers have resulted in higher NSRP when compared to the control binder over the range of test temperatures. The DNSRP analysis has shown that the critical temperature for NI.44P2 binder is $64^{\circ} \mathrm{C}$. Therefore, the best performance of nanomer I.44P in terms of NSRP factor is presented at this temperature. Additionally, it is suggested to characterize the effects of

12 Nano-materials on asphalt binder using VNSRP analysis for comparing the rutting resistance of modified binder to the control asphalt binder.

Although, traditional rheological properties, such as viscosity and $\mathrm{G}^{*} / \mathrm{sin} \delta$, can be used 15 to study the Nano-materials effects, it is important to have a parameter that is universally comparable. Therefore, the non-dimensional parameter, $\nabla \eta$ and $\nabla N S R P$ were proposed as unique

17 indicators to evaluate and compare the changes in the Nano-modified binders. These parameters merely show the percentage of change (negative or positive) per unit percentage of Nano19 material at each test temperature, compared to the boundary condition that is always based on the non-dimensional computation in the analysis. This will ensure the viscosity or $\mathrm{G}^{*} / \sin \delta$ values of

21 Nano-modified asphalt binders obtained in various researches are comparable when using 22 different types and sources of base binder. The $\nabla \eta$ and $\nabla N S R P$ values can be used as a 23 preliminary guidance to choose the ideal type and content of modifiers but these values are not 
1 only for the Nano-material application. The results from asphalt mixtures testing are also

2 necessary to consider to have a better understanding on the long term performance of asphalt

3 mixture prepared with Nano-material modifiers. Furthermore, the $\nabla \eta$-temperature and $\nabla N S R P-$

4 temperature relationships can be used to investigate the changes in the chosen rheological

5 properties versus temperature. Such trends can also be applied as an indicator to compare the

6 effects of Nano-material at a given temperature range.

7 The activation energy of the modified asphalt binders based on the RV testing results (at

8 high temperatures or when the asphalt binders are at viscous phase) were lower than those of the

9 modified binder obtained using the DSR (at intermediate temperatures when the binders are at

10 visco-elastic phase), which is due to the intermolecular forces of visco-elastic asphalt binders

11 being much higher than those of the asphalt binders in the viscous phase. Activation energy

12 analysis results indicate that the amount of energy required by the modified asphalt binders is

13 dependent on the type and content of Nano-materials, as well as the physical phase of the binder

14 sample which is directly influenced by temperature.

\section{Acknowledgements}

This material is based in part upon work supported by the National Science Foundation

18 under grants 0936726. The experimental work was completed at the Highway Engineering

19 Laboratory at Universiti Sains Malaysia (USM). Many thanks are also due to the technicians of

20 the Highway Engineering Laboratory at USM. Any opinions, findings and conclusions expressed

21 in this material are those of the author's and do not necessarily reflect the views of the National

22 Science Foundation. 
1

2 1. Chong, K.P. Nanotechnology and information technology in civil engineering. 2004.

\section{References} ASCE.

2. Sanchez, F. and K. Sobolev, Nanotechnology in concrete-a review. Construction and Building Materials, 2010. 24(11): p. 2060-2071.

3. Yao, H., Z. You, L. Li, C.H. Lee, D. Wingard, Y.K. Yap, X. Shi, and S.W. Goh, Properties and Chemical Bonding of Asphalt and Asphalt Mixtures Modified with Nanosilica. Journal of Materials in Civil Engineering, 2012.

4. Al-Rub, R.K.A., Nanotechnology-Based System for Damage-Resistant Concrete Pavements. 2012.

5. Mulenga, D. and P. Robery. Can Nanotechnology Address Todays Civil Engineering Challenges? in Structures Congress 2010. 2010. ASCE.

6. You, Z., J. Mills-Beale, J.M. Foley, S. Roy, G.M. Odegard, Q. Dai, and S.W. Goh, Nanoclay-modified asphalt materials: Preparation and characterization. Construction and Building Materials, 2011. 25(2): p. 1072-1078.

7. Lazzara, G. and S. Milioto, Dispersions of nanosilica in biocompatible copolymers. Polymer Degradation and Stability, 2010. 95(4): p. 610-617.

8. Khattak, M.J., A. Khattab, and H.R. Rizvi. Mechanistic Characteristics of Asphalt Binder and Asphalt Matrix Modified with Nano-Fibers. in Geo-Frontiers Congress 2011. 2011.

9. Khattak, M.J., A. Khattab, H.R. Rizvi, and P. Zhang, The impact of carbon nano-fiber modification on asphalt binder rheology. Construction and Building Materials, 2012. 30: p. 257-264. 
10. Motlagh, A.A., A. Kiasat, E. Mirzaei, and F.O. Birgani, Bitumen Modification Using Carbon Nanotubes. World Applied Sciences Journal, 2012. 18(4): p. 594-599.

11. Shirakawa, T., A. Tada, and N. Okazaki, Development of Functional Carbon NanotubesAsphalt Composites.

12. Santagata, E., O. Baglieri, L. Tsantilis, and D. Dalmazzo, Rheological Characterization of Bituminous Binders Modified with Carbon Nanotubes. Procedia-Social and Behavioral Sciences, 2012. 53: p. 546-555.

13. Shiman, L., A. Shiman, N. Spitsyna, and A. Lobach, Effects of Nanocomposites on the High Temperature Rheological Properties of a PG58 Asphalt-Binder. Hunan, China, ASCE, 2011.

14. Jahromi, S.G. and A. Khodaii, Effects of nanoclay on rheological properties of bitumen binder. Construction and Building Materials, 2009. 23(8): p. 2894-2904.

15. Yao, H., Z. You, L. Li, X. Shi, S.W. Goh, J. Mills-Beale, and D. Wingard, Performance of asphalt binder blended with non-modified and polymer-modified nanoclay. Construction and Building Materials, 2012. 35: p. 159-170.

16. Yao, H., Z. You, L. Li, S.W. Goh, C.H. Lee, Y.K. Yap, and X. Shi, Rheological properties and chemical analysis of nanoclay and carbon microfiber modified asphalt with Fourier transform infrared spectroscopy. Construction and Building Materials, 2013. 38: p. 327-337.

17. Shi, X., S.W. Goh, M. Akin, S. Stevens, and Z. You, Exploring the Interactions of Chloride Deicer Solutions with Nano/Micro-Modified Asphalt Mixtures Using Artificial Neural Networks. Journal of Materials in Civil Engineering, 2011. 
1 18. Cheng, J., J. Shen, and F. Xiao, Moisture susceptibility of warm-mix asphalt mixtures containing nanosized hydrated lime. Journal of Materials in Civil Engineering, 2011. 23(11): p. 1552-1559.

19. Nazzal, M.D., S. Kaya, T. Gunay, and P. Ahmedzade, Fundamental Characterization of Asphalt Clay Nanocomposites. Journal of Nanomechanics and Micromechanics, 2012. 3(1): p. 1-8.

20. Goh, S.W., M. Akin, Z. You, and X. Shi, Effect of deicing solutions on the tensile strength of micro-or nano-modified asphalt mixture. Construction and Building Materials, 2011. 25(1): p. 195-200.

21. Jamal Khattak, M., A. Khattab, and H. R Rizvi, Characterization of carbon nano-fiber modified hot mix asphalt mixtures. Construction and Building Materials, 2013. 40: p. 738-745.

22. Pacheco-Torgal, F. and S. Jalali, Nanotechnology: advantages and drawbacks in the field of construction and building materials. Construction and Building Materials, 2011. 25(2): p. 582-590.

23. Haider, S.W., M.W. Mirze, A.K. Thottempudi, J. Bari, and G.Y. Baladi. Characterizing Temperature Susceptibility of Asphalt Binders Using Activation Energy Flow. in Transportation and Development Institute Congress 2011: Integrated Transportation and Development for a Better Tomorrow. 2011. Chicago, Illinois.

24. Hamzah, M.O., A. Jamshidi, K. Kanitpong, and M.Y. Aman, Parameters to characterise the effects of Sasobit ${ }^{\circledR}$ content on the rheological properties of unaged and aged asphalt binders. Road materials and pavement design, 2012. 13(2): p. 368-375. 
3 List of Figures

4 Fig. 1. Effects of asphalt binder types or sources on the rheological properties

5 Fig. 2. Appearance of Nano-material modifiers used in this study (a) NS, (b) NPMN, (c) MCF,

6 (d) PMN and (e) NI.44P

7 Fig. 3. Schematic illustration of intermolecular force and activation energy in the asphalt binder

8 Fig. 4. Viscosity-temperature dependency for asphalt binders incorporating different Nano-

9 materials types and contents (a) MCF, (b) NPMN, (c) PMN, (d) NI.44P and (e) NS

10 Fig. 5. Temperature versus non-dimensional viscosity index ( $\nabla \eta)$ for (a) MCF, (b) NPMN, (c)

11 NI.44P, (d) PMN and (e) NS

12 Fig. 6. Effects of modifiers on $\mathrm{G}^{*}$ and $\delta$ for (a) MCF, (b) NPMN, (c) NI.44P, (d) PMN and (e)

13 NS

14 Fig. 7. Effects of modifiers on $\mathrm{G}^{*}$ and $\delta$ for (a) MCF, (b) NPMN, (c) NI.44P, (d) PMN and (e)

$15 \quad \mathrm{NS}$ at different frequencies at $58^{\circ} \mathrm{C}$

16 Fig. 8. $G^{*} / \sin \delta$ versus temperature for various Nano-modified binder samples

17 Fig. 9. $\nabla N S R P$ for the asphalt binders incorporating the Nano-materials a) MCF, (b) NPMN, (c)

18 NI.44P, (d) PMN and (e) NS

19

20

21 


\section{$3 \quad$ List of Tables}

4 Table 1. Example computations of reduction in the relative viscosity

5 Table 2. Types of modifier used in this study

6 Table 3. Construction temperatures of asphalt mixtures incorporating various Nano-materials

7 types and contents

8 Table 4. Amounts of activation energy of the asphalt binder samples using RV result

9 Table 5. Amounts of activation energy of the asphalt binder samples using DSR result 10 


\section{Graphical Abstract}

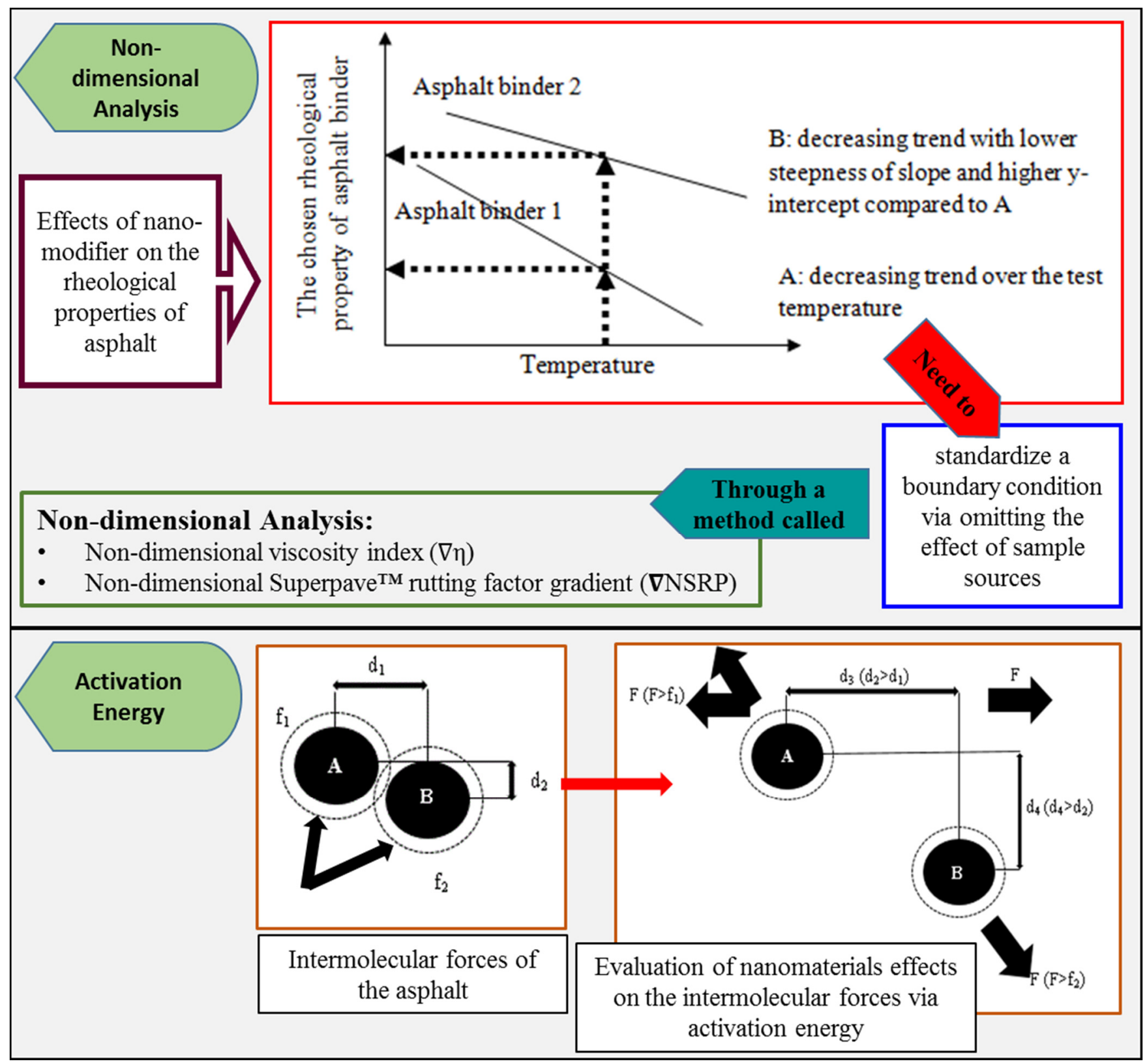


1 Table 1. Example computations of reduction in the relative viscosity

2

\begin{tabular}{|c|c|c|c|c|c|c|c|c|c|c|}
\hline \multirow{4}{*}{$\begin{array}{l}\mathrm{T}^{*} \\
\left({ }^{\circ} \mathrm{C}\right)\end{array}$} & \multicolumn{4}{|c|}{ Viscosity (mPa's) } & \multicolumn{4}{|c|}{ Relative viscosity (\%) } & \multirow{2}{*}{\multicolumn{2}{|c|}{$\begin{array}{l}\text { Reduction in the } \\
\text { relative viscosity } \\
(\%) \\
\text { Modified } \\
\text { Binder**** }\end{array}$}} \\
\hline & \multicolumn{2}{|c|}{$\begin{array}{c}\text { Un-modified } \\
\text { Binder (control) }\end{array}$} & \multicolumn{2}{|c|}{$\begin{array}{l}\text { Modified } \\
\text { Binder }\end{array}$} & \multicolumn{2}{|c|}{$\begin{array}{c}\text { Un-modified } \\
\text { Binder** }\end{array}$} & \multicolumn{2}{|c|}{$\begin{array}{c}\text { Modified } \\
\text { Binder**** }\end{array}$} & & \\
\hline & 1 & 2 & 3 & 4 & 5 & 6 & 7 & 8 & 9 & 10 \\
\hline & $\begin{array}{l}\text { Asphalt } \\
\text { A }\end{array}$ & $\begin{array}{c}\text { Asphalt } \\
\text { B }\end{array}$ & $\begin{array}{l}\text { Asphalt } \\
\text { A }\end{array}$ & $\begin{array}{c}\text { Asphalt } \\
\text { B }\end{array}$ & $\begin{array}{l}\text { Asphalt } \\
\text { A }\end{array}$ & $\begin{array}{c}\text { Asphalt } \\
\text { B }\end{array}$ & $\begin{array}{c}\text { Asphalt } \\
\text { A }\end{array}$ & $\begin{array}{c}\text { Asphalt } \\
\text { B }\end{array}$ & $\begin{array}{l}\text { Asphalt } \\
\text { A }\end{array}$ & $\begin{array}{l}\text { Asphalt } \\
\text { B }\end{array}$ \\
\hline 120 & 980 & 1100 & 880 & 970 & 1 & 1 & 0.897 & 0.881 & -10.20 & -11.81 \\
\hline 140 & 300 & 420 & 250 & 350 & 1 & 1 & 0.833 & 0.833 & -16.67 & -16.67 \\
\hline 150 & 120 & 180 & 100 & 140 & 1 & 1 & 0.833 & 0.777 & -16.67 & -22.22 \\
\hline $\begin{array}{l}*: \text { Tem } \\
* *: \text { On } \\
* * *: \mathrm{V} \\
0.89 \text { as } \\
* * * *: \\
\text { calcula }\end{array}$ & $\begin{array}{l}\text { erature } \\
\text { itting the ef } \\
\text { scosity valu } \\
\text { presented ir } \\
\text { anges in th } \\
\text { ion is used }\end{array}$ & $\begin{array}{l}\text { s in colum } \\
\text { column } 7 \\
\text { reduction } \\
\text { or values in }\end{array}$ & $\begin{array}{l}3 \text { and } 4 \text { a } \\
\text { relative } v \\
\text { lumn } 10\end{array}$ & cosity: ( & mn 7 -colum & $\begin{array}{l}\text { onder } \\
* 10\end{array}$ & $\begin{array}{l}\text { 5). } \\
\text { nns } 1 \\
\text { resul }\end{array}$ & respe & unm & $\begin{array}{l}80= \\
\text { same }\end{array}$ \\
\hline
\end{tabular}

3

4

5

6

7

8

9

10

11

12

13

14

15

16 
1 Table 2. Types of modifier used in this study

\begin{tabular}{cccc}
\hline Types of Modifier & Description & \% Modifier Used & Sample Designated \\
\hline \multirow{2}{*}{ PMN } & Polymer Modified & $2 \%$ & $2 \% \mathrm{PMN}$ \\
& Nano-clay & $4 \%$ & $4 \% \mathrm{PMN}$ \\
\hline \multirow{2}{*}{ NPMN } & Non-Modified & $2 \%$ & $2 \% \mathrm{NPMN}$ \\
& Polymer Nano-clay & $4 \%$ & $4 \% \mathrm{NPMN}$ \\
\hline \multirow{2}{*}{$\mathrm{MCF}$} & \multirow{2}{*}{ Carbon Micro-Fiber } & $2 \%$ & $2 \% \mathrm{MCF}$ \\
& \multirow{2}{*}{$\mathrm{NI} 44 \mathrm{P}$} & $4 \%$ & $4 \% \mathrm{MCF}$ \\
\hline \multirow{2}{*}{$\mathrm{NS}$} & NanomerI.44P & $2 \%$ & $2 \% \mathrm{~N} 144 \mathrm{P}$ \\
& \multirow{2}{*}{ Nano-Silica } & $4 \%$ & $4 \% \mathrm{~N} 144 \mathrm{P}$ \\
& & $4 \%$ & $4 \% \mathrm{NS}$ \\
& & $6 \%$ & \\
\hline
\end{tabular}

2

3

4

5

6

7

8

9

10

11

12

13

14

15

16

17 
1 Table 3. Construction temperatures of asphalt mixtures incorporating various Nano-materials

2 types and contents

\begin{tabular}{cccccccccc}
\hline \multirow{2}{*}{$\begin{array}{c}\text { Construction } \\
\text { Temperature } \\
\left({ }^{\circ} \mathrm{C}\right)\end{array}$} & $\begin{array}{c}\text { Control } \\
\text { binder }\end{array}$ & \multicolumn{2}{c}{ MCF } & \multicolumn{2}{c}{ PMN } & \multicolumn{2}{c}{ NPMN } & \multicolumn{2}{c}{ NS } \\
\cline { 2 - 10 } & $2 \%$ & $4 \%$ & $2 \%$ & $4 \%$ & $2 \%$ & $4 \%$ & $4 \%$ & $6 \%$ \\
\hline Mixing & 170 & 172 & 174 & 168 & 166 & 182 & 195 & 168 & 168 \\
\hline Compaction & 150 & 158 & 160 & 156 & 150 & 166 & 178 & 150 & 150 \\
\hline
\end{tabular}

3

4

5

6

7

8

9

10

11

12

13

14

15 
1 Table 4. Amounts of activation energy of the asphalt binder samples using RV result

\begin{tabular}{|c|c|c|c|}
\hline Asphalt binder & $\begin{array}{l}\text { Activation energy } \\
\qquad(\mathrm{kJ} / \mathrm{mol})\end{array}$ & $\begin{array}{c}\text { Effect of nano-material }^{1} \\
(\%)\end{array}$ & $\begin{array}{l}\text { Effect of Nano- } \\
\text { material content } \\
(\%)\end{array}$ \\
\hline Control Binder & 57754.03 & - & - \\
\hline MCF2 & 63367.64 & 9.71 & \multirow{2}{*}{-6.59} \\
\hline MCF4 & 59187.36 & 2.48 & \\
\hline NPMN2 & 66543.59 & 15.21 & \multirow{2}{*}{9.41} \\
\hline NPMN4 & 72808.19 & 26.06 & \\
\hline PMN2 & 59818.39 & 3.574 & \multirow{2}{*}{-3.51} \\
\hline PMN4 & 57717.45 & -0.06 & \\
\hline NI.44P2 & 57931.12 & 0.30 & \multirow{2}{*}{10.47} \\
\hline NI.44P4 & 64001.17 & 10.81 & \\
\hline NS4 & 60963.23 & 5.55 & \multirow{2}{*}{-8.82} \\
\hline NS6 & 55580.75 & -3.76 & \\
\hline
\end{tabular}


Table 5. Amounts of activation energy of the asphalt binder samples using DSR result

\begin{tabular}{cccc}
\hline Asphalt binder & $\begin{array}{c}\text { Activation energy } \\
(\mathrm{kJ} / \mathrm{mol})\end{array}$ & $\begin{array}{c}\text { Effect of nano-material } \\
(\%)\end{array}$ & $\begin{array}{c}\text { Effect of Nano- } \\
\text { material content } \\
(\%)\end{array}$ \\
\hline Control Binder & 88161.65 & - & - \\
\hline MCF2 & 89866.02 & 1.93 & -4.83 \\
\hline MCF4 & 85526.11 & -2.98 & \multirow{2}{*}{1.25} \\
\hline NPMN2 & 85268.38 & -3.28 & \multirow{2}{*}{-2.48} \\
\hline NPMN4 & 86340.89 & -2.06 & 1.19 \\
\hline PMN2 & 88036.94 & -0.14 & \multirow{2}{*}{1.31} \\
\hline PMN4 & 85850.36 & -2.62 & \\
\hline NI.44P2 & 90323.29 & 2.45 & \\
\hline NI.44P4 & 91404.11 & 3.67 & \\
\hline NS4 & 90747.31 & 2.93 & 1.58 \\
\hline NS6 & 89558.41 & & \\
\hline${ }^{2}:$ Change percentage in activation energy of the Nano-material-modified and control asphalt binders. & \\
\hline & & & \\
\hline & & & \\
\hline
\end{tabular}


1

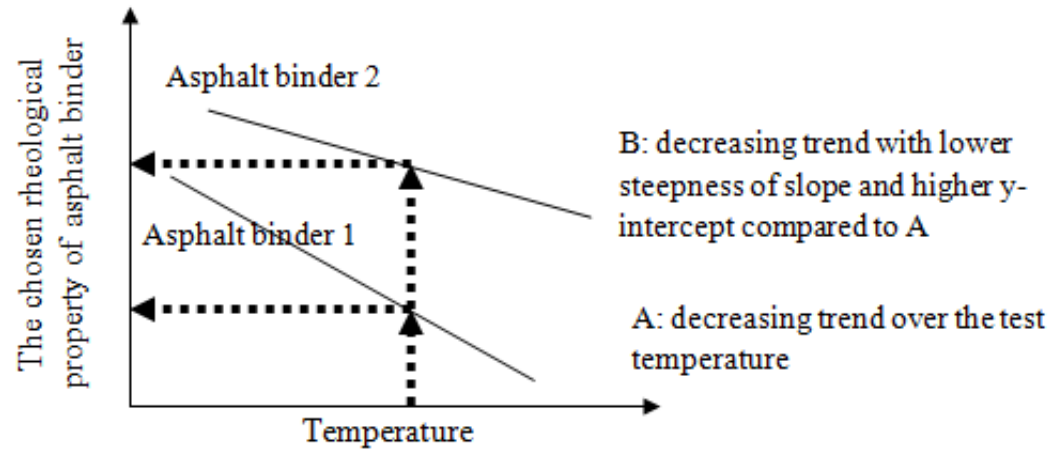

2 Fig. 1. Effects of asphalt binder types or sources on the rheological properties

3

4

5

6

7

8

9

10

11

12

13

14

15

16

17

18

19 


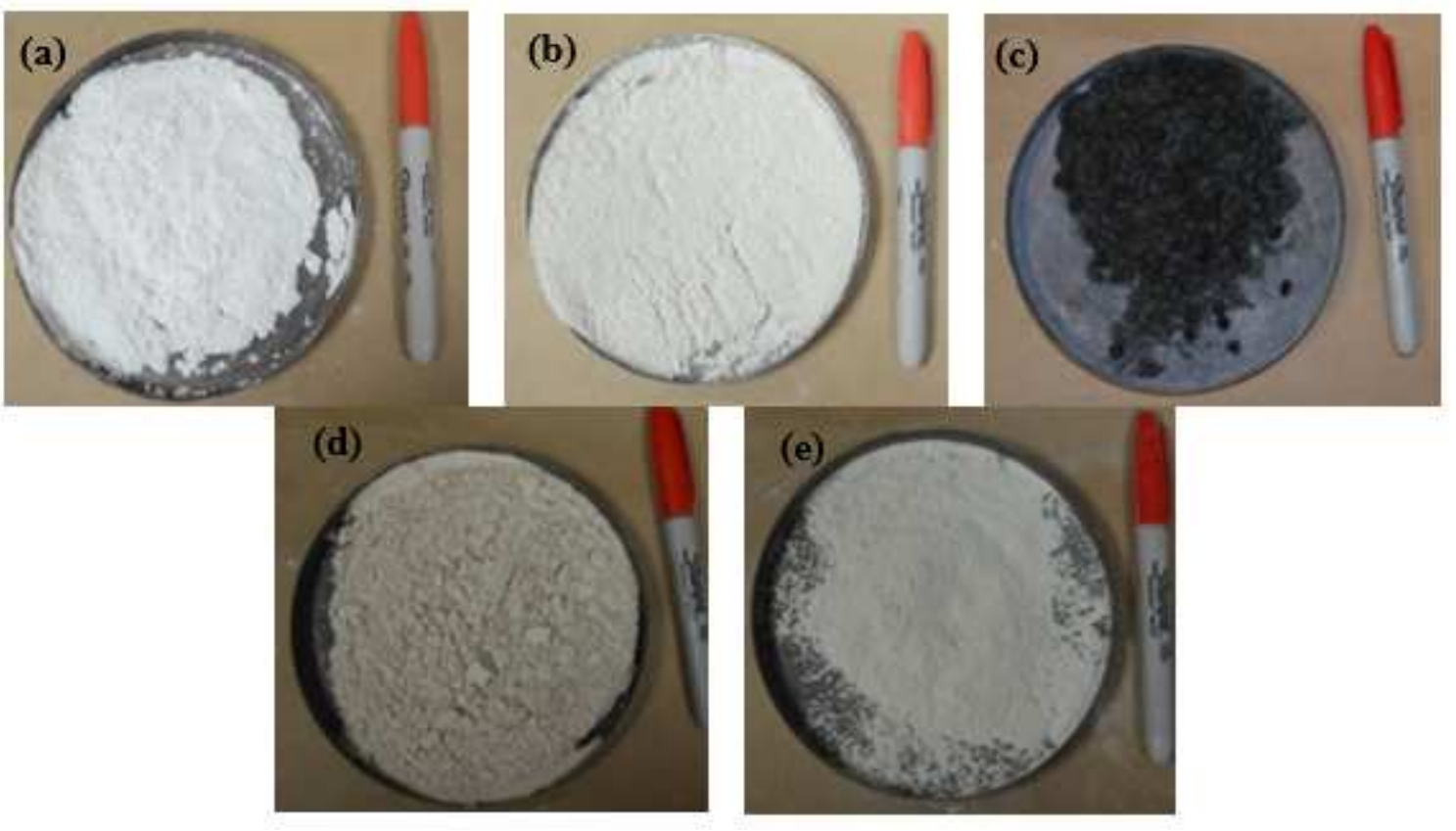

2 Fig. 2. Appearance of Nano-material modifiers used in this study (a) NS, (b) NPMN, (c) MCF,

3 (d) PMN and (e) NI.44P

4

5

6

7

8

9

10

11

12

13

14

15 


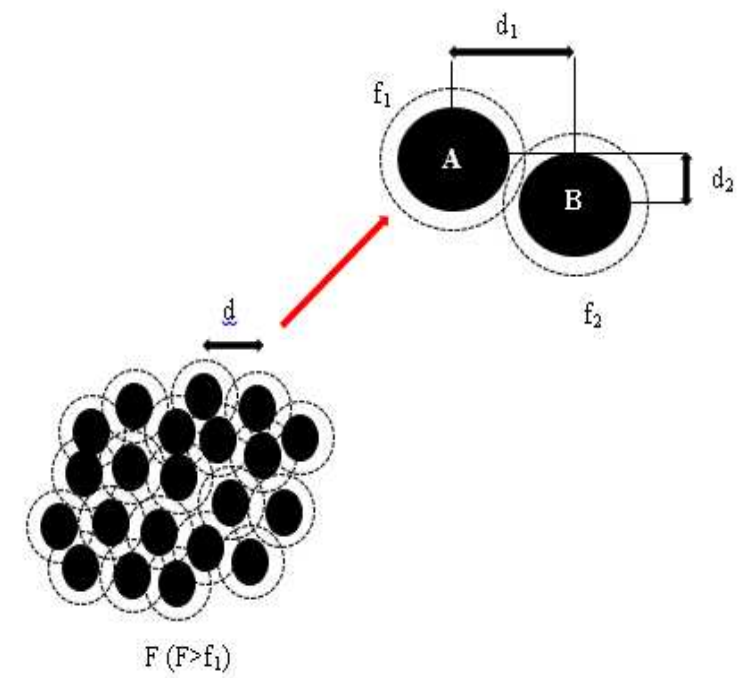

(a) Intermolecular force of asphalt molecules

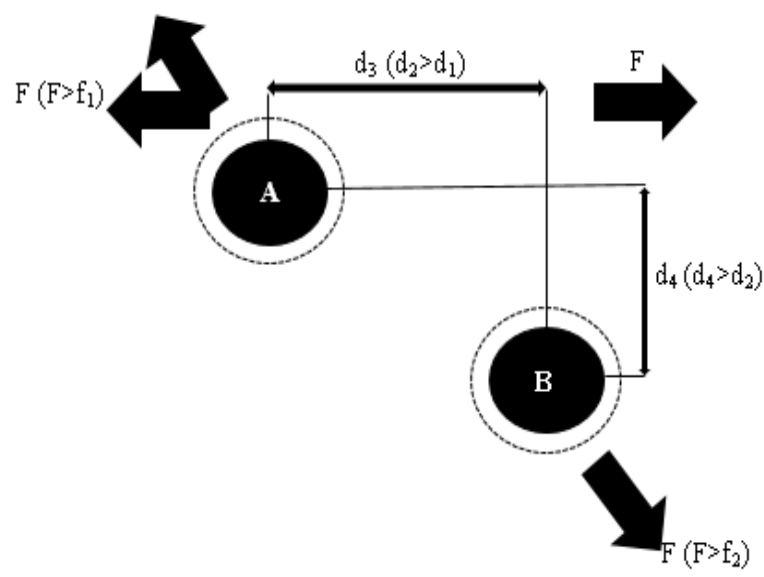

(b) Required force to overcome intermolecular forces

Fig. 3. Schematic illustration of intermolecular force and activation energy in the asphalt binder 

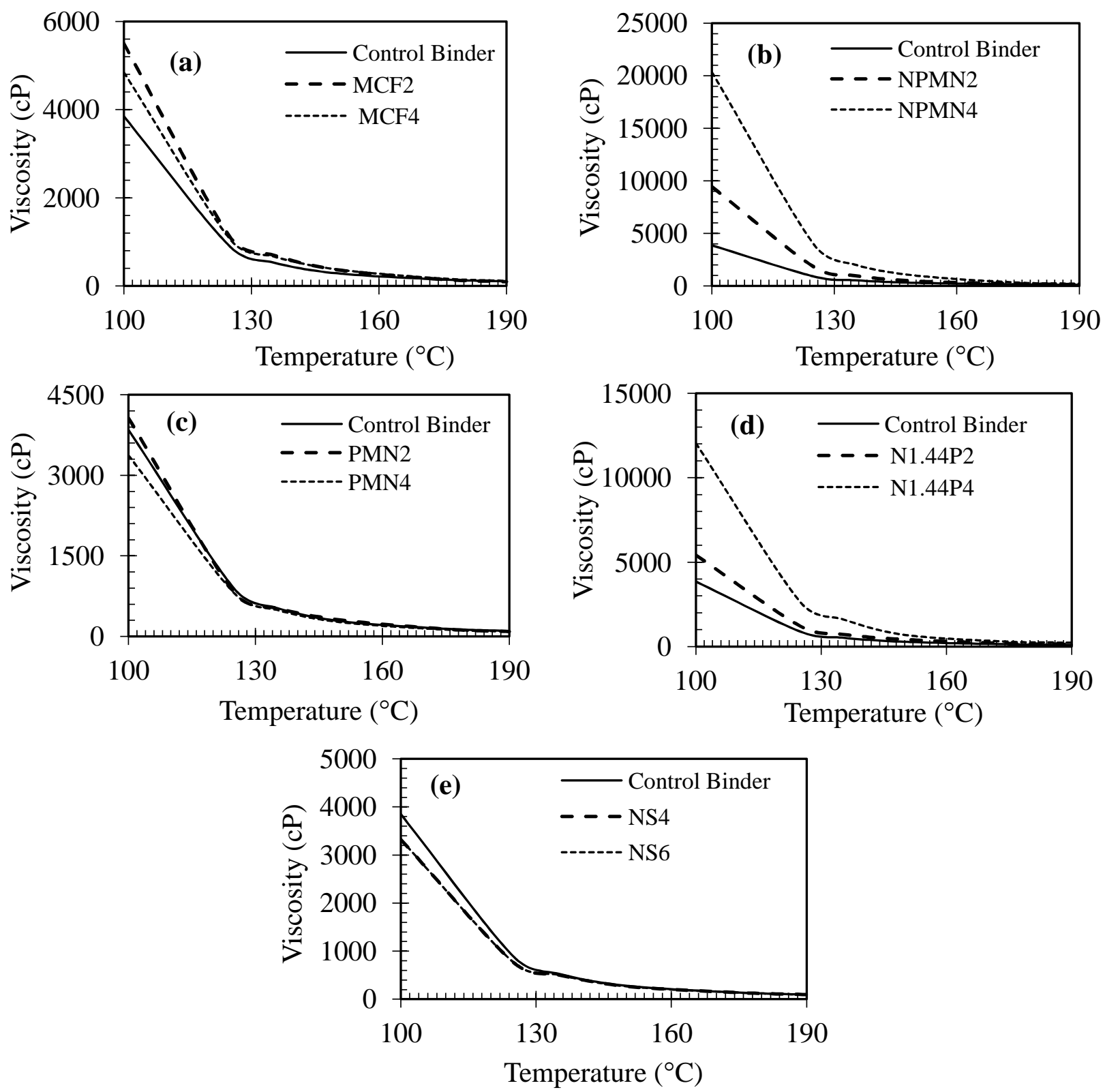

2 Fig. 4. Viscosity-temperature dependency for asphalt binders incorporating different Nano-

3 materials types and contents (a) MCF, (b) NPMN, (c) PMN, (d) NI.44P and (e) NS

4 

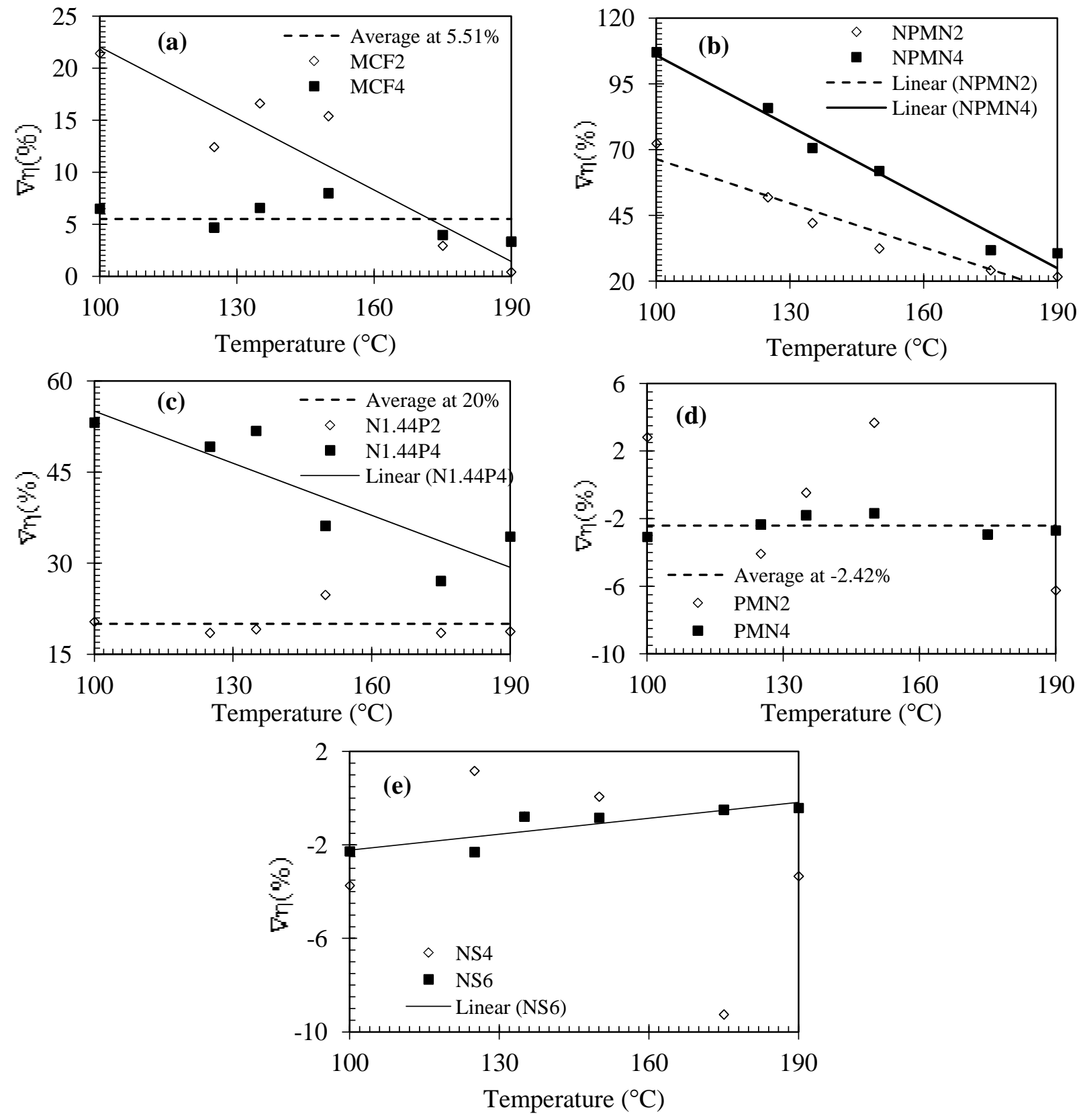

2 Fig. 5. Temperature versus non-dimensional viscosity index ( $\nabla \eta$ ) for (a) MCF, (b) NPMN, (c)

$3 \quad$ NI.44P, (d) PMN and (e) NS 

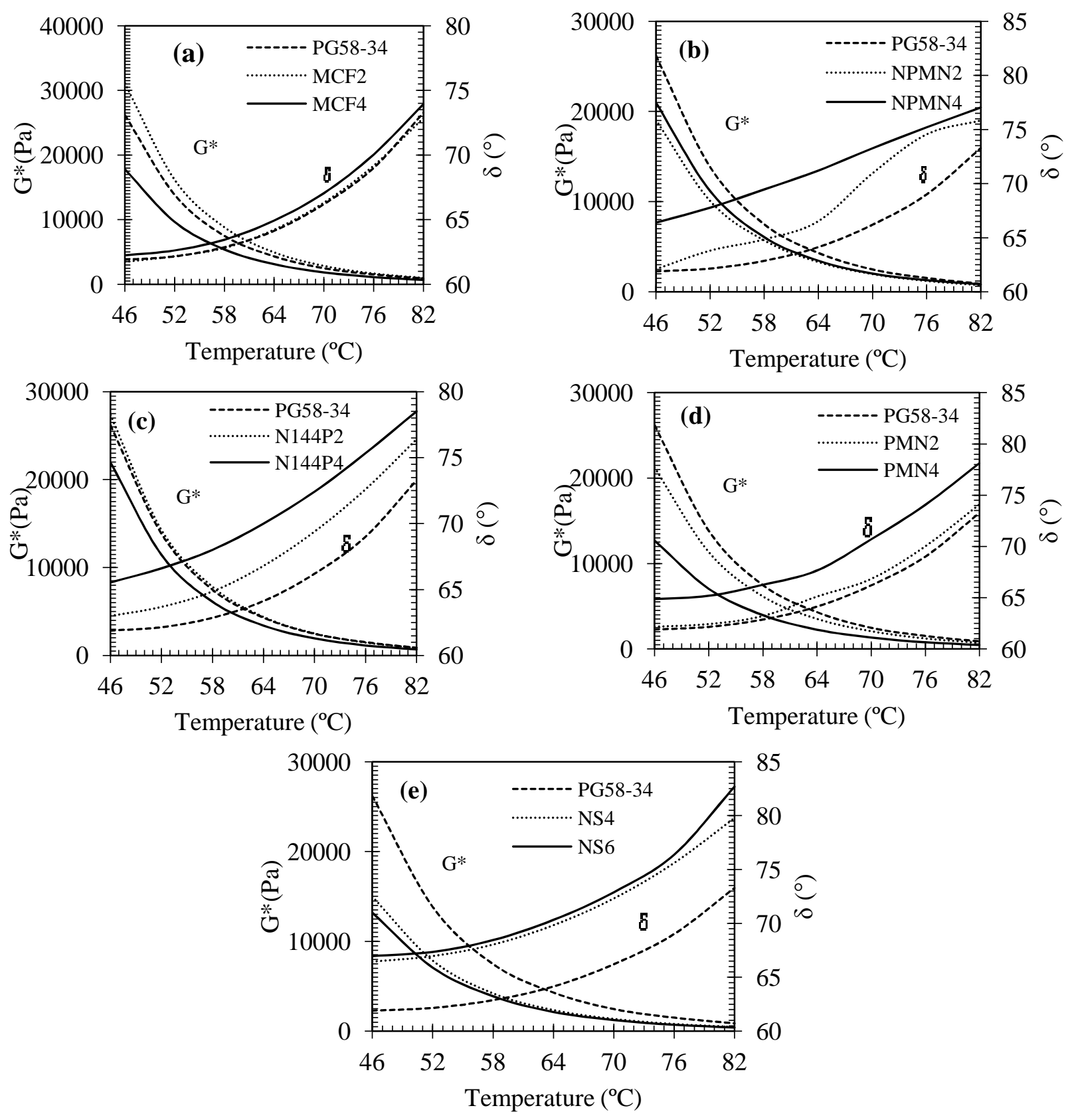

1 Fig. 6. Effects of modifiers on $\mathrm{G}^{*}$ and $\delta$ for (a) MCF, (b) NPMN, (c) NI.44P, (d) PMN and (e)

$2 \mathrm{NS}$ 

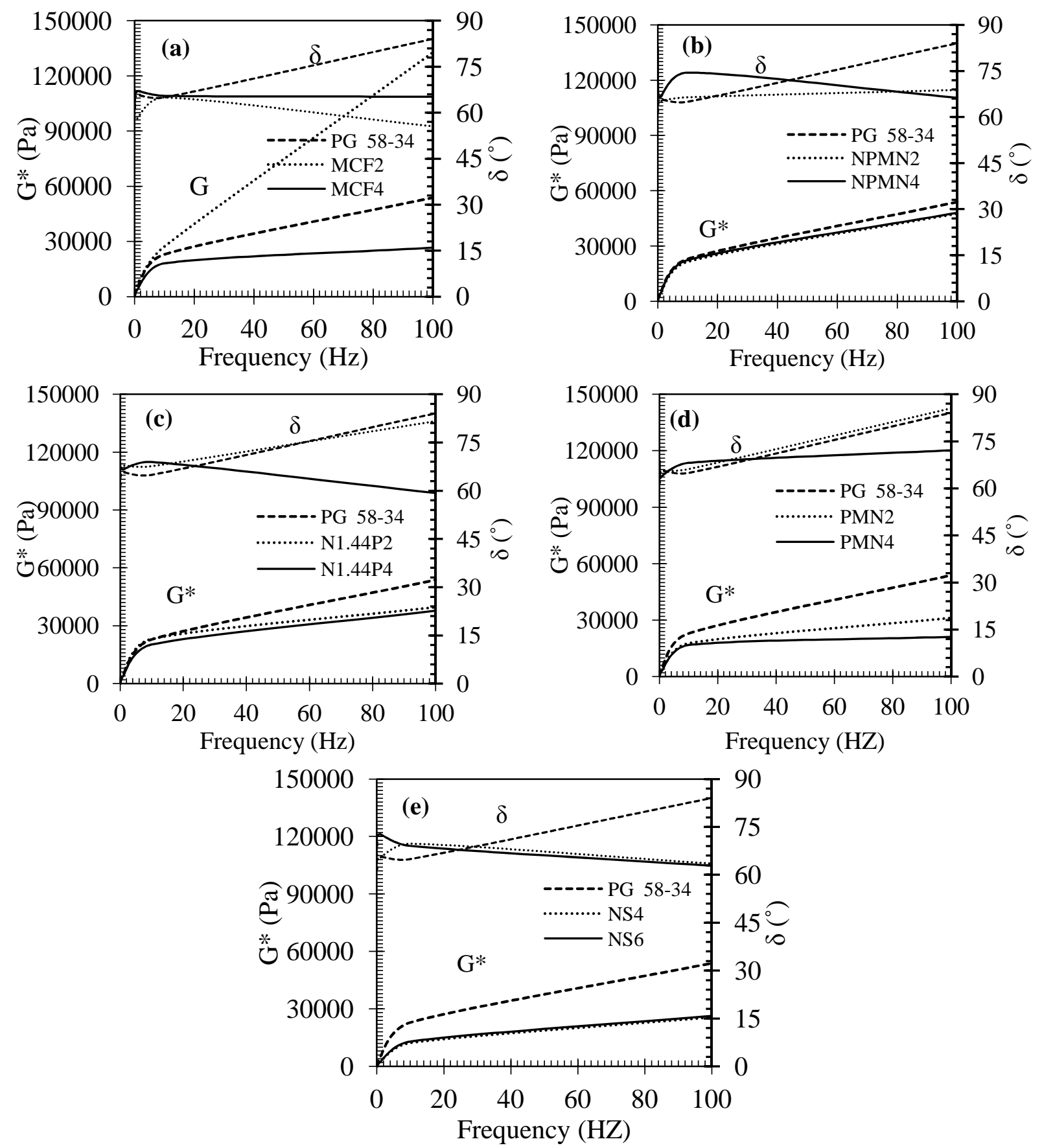

2 Fig. 7. Effects of modifiers on $\mathrm{G}^{*}$ and $\delta$ for (a) MCF, (b) NPMN, (c) NI.44P, (d) PMN and (e)

$3 \quad \mathrm{NS}$ at different frequencies at $58^{\circ} \mathrm{C}$ 

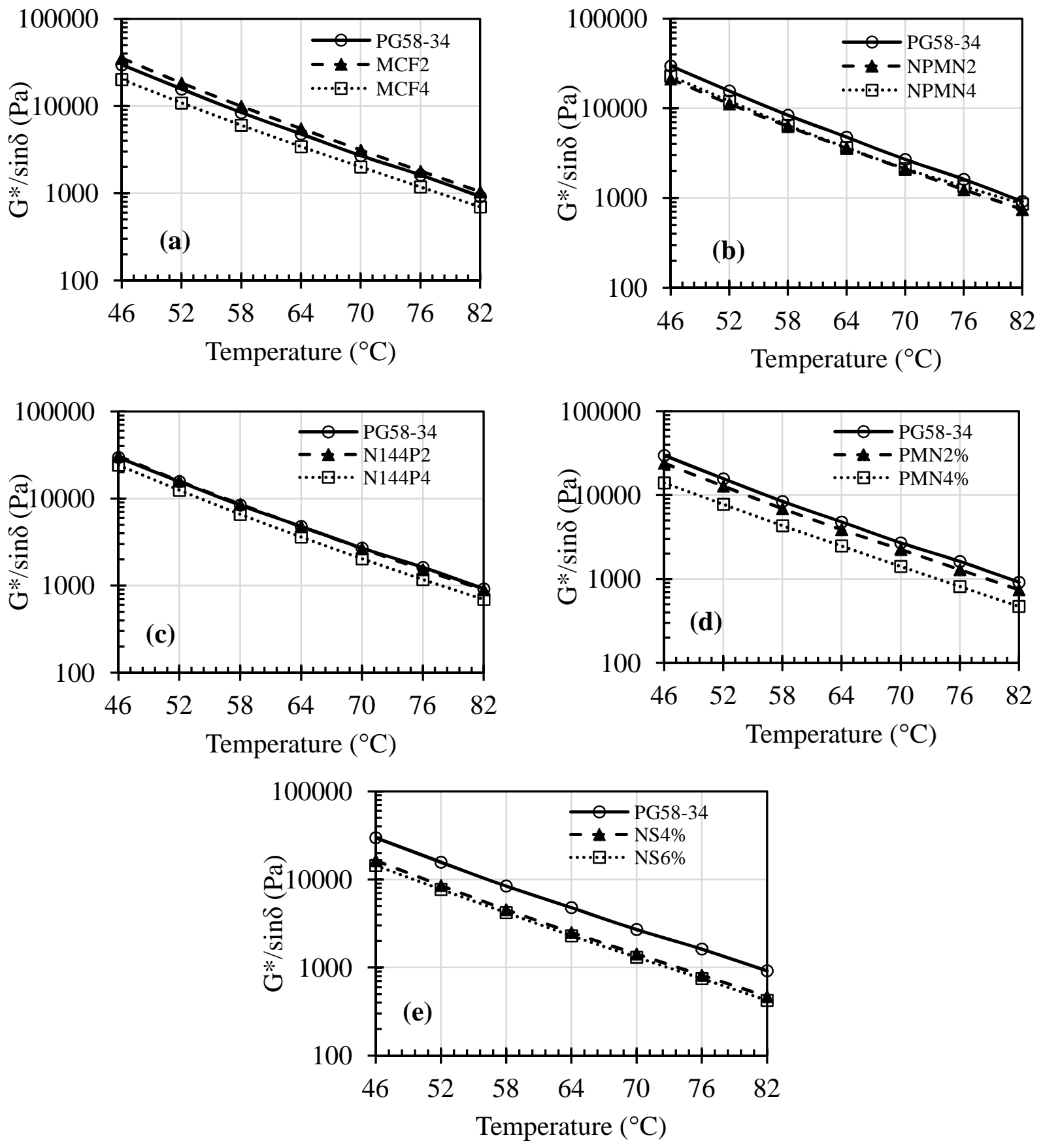

2 Fig. 8. $G^{*} / \sin \delta$ versus temperature for various Nano-modified binder samples 

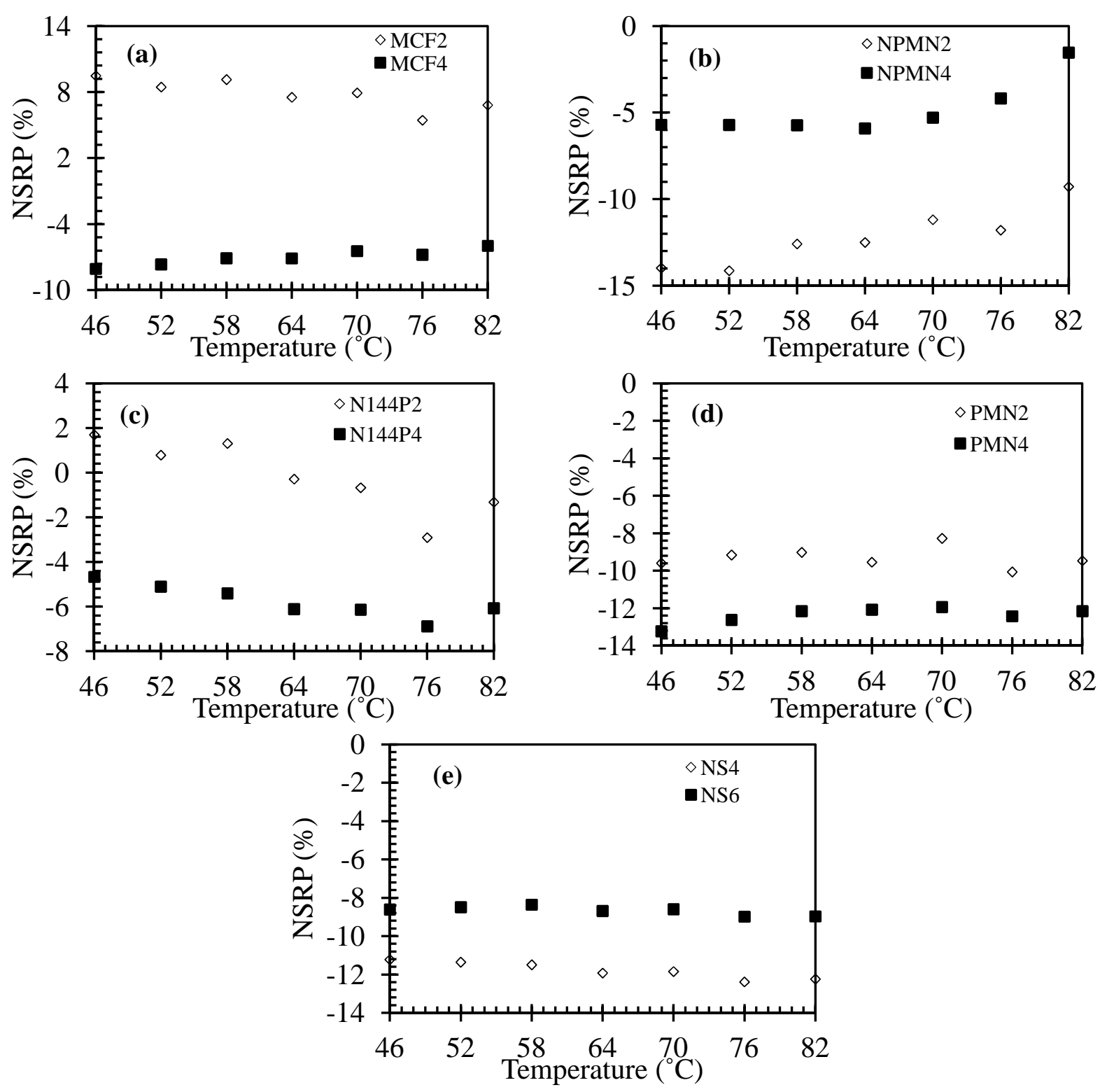

1

2 Fig. 9. $\nabla N S R P$ for the asphalt binders incorporating the Nano-materials a) MCF, (b) NPMN, (c)

$3 \quad$ NI.44P, (d) PMN and (e) NS 